bolischen Bahnen der hellen Meteore sei, jedenfalls möchte noch ein Beobachtungsversuch in Vorschlag zo bringen sein, welcher, wie ich glaube, geeignet sein könnte, die hierher gehörigen Fragen einer Entscheidung etwas näher zu bringen, und welcher sich anf die August- und November-Meteore bezieht. Es würde sich darum handeln, bei einer Anzahl von Sternschnuppen der Systeme der Perseiden und der Leoniden möglichst genaue Schätrungen der Dauer zu erlangen oder we:igstens des Maximums dieser Daner (unter gleichzeitiger Beobachtung von An- fangspunkt und Endpunkt), um bei diesen Meteoren zu erfahren, ob die directe Beobachtung der Geschwindigkeit denjenigen elliptischen Bahnen annähernd entspricht, in welchen dieselben nach der Entdeckung Schiaparelli's factis $h$ sich bewegen. Sollten auch hier für die Darstellung der Beobachtungen hyperbolis $\cdot$ he Bahnen nothwendig werden, so würde alsdann die Annahme besonderer in der Erdnähe sich geltend machender Kräfte nicht wohl vermieden werden können.

Breslau, 1874, Febr. 2.

J. G. Galle.

\title{
Elemente und Ephemeride des Planeten (127).
}

J'ai l'honneur de vous communiquer de nouveaux éléments de la planète (127), que j'ai calculés en tenant compte de sept observations équatoriales faites à l'observatoire de Paris et d'une faite à l'observatoire de Marscille pendant l'opposition de $1872-73$. De ces éléments j'ai déduit une éphéméride de la planète pour le mois de Mai.

Eléments de la planète (127).

1872 Avril 17.0 Temps moy. de Greenwich.
Anomalie moyenne $=35^{0} \quad 4^{\prime} 10^{\prime \prime} 6$

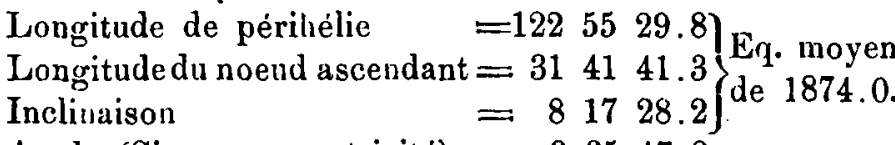
Angle (Sinus =excentricité) $=$\begin{tabular}{l}
33547.8 \\
\hline
\end{tabular}
Moyen mouvement diurne $=776.37$
Log $a$
$=0.4399592$.

Ephéméride pour midi moyen de Greenwich.

\begin{tabular}{|c|c|c|c|}
\hline 374. & As $:$ droite appar. & Décl. appar. & $\log \triangle$ \\
\hline ril 2 & $9^{\mathrm{h}} 53^{\mathrm{m}} 21^{\mathrm{s}} .5$ & $+20^{\circ} 34^{\prime} 38^{\prime \prime}$ & 0.3360 \\
\hline 2 & 5350.7 & +202741 & 0.3386 \\
\hline 3 & 5421.9 & +202039 & 0.3411 \\
\hline [ai & $54 \quad 52.9$ & +201333 & 0.3436 \\
\hline & $\begin{array}{ll}55 & 25.9\end{array}$ & +20622 & 0.3461 \\
\hline & $56 \quad 0.0$ & +19597 & 0.3486 \\
\hline & 5635.4 & +195147 & 0.3511 \\
\hline & $\begin{array}{ll}57 & 11.9\end{array}$ & +194423 & 0.3536 \\
\hline & 5749.5 & +193655 & 0.3561 \\
\hline & 5828.2 & +192922 & 0.3586 \\
\hline & 598.0 & +192144 & 0.3611 \\
\hline & $59 \quad 48.9$ & +19143 & 0.3636 \\
\hline
\end{tabular}

1874. Asc. droite appar. Décl. appar. Log $\Delta$ Avril $10 \quad 10 \quad 0 \quad 30.9$

0.3661

\begin{tabular}{|c|c|c|c|}
\hline 11 & 113.9 & +185829 & 0.3685 \\
\hline 12 & 157.9 & +185036 & 0.3709 \\
\hline 13 & 243.0 & +184239 & 0.3733 \\
\hline 14 & 329.1 & +183438 & 0.3757 \\
\hline 15 & 416.2 & +182634 & 0.3781 \\
\hline 16 & $\begin{array}{ll}5 & 4.2\end{array}$ & +181826 & 0.3805 \\
\hline 17 & $\begin{array}{ll}5 & 53.2\end{array}$ & +181014 & 0.3829 \\
\hline 18 & 643.1 & +18158 & 0.3853 \\
\hline 19 & 733.8 & +175337 & 0.3876 \\
\hline 20 & 825.4 & +174514 & 0.3900 \\
\hline 21 & $\begin{array}{lll}9 & 17.9\end{array}$ & +173647 & 03933 \\
\hline 22 & 1011.3 & +172817 & 0.3946 \\
\hline 23 & 115.5 & +171944 & 0.3969 \\
\hline 24 & 120.5 & +17118 & 0.3992 \\
\hline 25 & 1256.4 & +17228 & 0.4015 \\
\hline 26 & 1352.9 & +165345 & 0.4038 \\
\hline 27 & 1450.1 & +164459 & 0.4038 \\
\hline 28 & 1548.1 & +163610 & 0.4082 \\
\hline 29 & 1646.8 & +162717 & 0.4104 \\
\hline 30 & 1746.3 & +161820 & 0.412 \\
\hline 31 & 1846.5 & +16922 & 0.414 \\
\hline
\end{tabular}

Au moyen de cette éphéméride la planète a été retrouvée à l'observatoire de Paris par les MM. Henry dans la nuit du 17. Avril.

La correction de l'éphéméride était pour ce jour: en AR. $+2 \mathrm{~m} 43 \mathrm{~s}$. en Décl. - 16'.

La grandeur de la planète était ce jour là 11.5 faible. Paris, 24. Avril 1874.

Henry Renan, Aide-astronome à l'observatoire de Paris. 